\title{
Experiments on initial stages of development of dam-break waves
}

\section{Análise experimental dos estágios iniciais da onda de ruptura de uma barragem}

\author{
Lélis Espartel $^{1}$ (D) \& Rafael Manica ${ }^{1}$ (D) \\ ${ }^{1}$ Universidade Federal do Rio Grande do Sul, Porto Alegre, RS, Brasil \\ E-mails: lelisespartel@gmail.com (LE),manica@iph.ufrgs.br (RM)
}

Received: June 30, 2020 - Revised: December 06, 2020 - Accepted: January 06, 2021

\begin{abstract}
The initial stages of instantaneous dam-break waves are here evaluated spatially and temporally through 36 physical experiments. Different conditions were tested for downstream $(J)$ and upstream $(M)$ water depths and their ratios $(r)$ to approach realistic conditions for prototype dams. Two non-dimensional parameters are proposed - effective height $\left(H_{E F}\right)$ and effective velocity $\left(V_{E F}\right)$ - to evaluate water depths and velocity peaks along the dam-break wave evolution. The maximum wave height is estimated as a function of $r$, whereas the $H_{E F}$ is inversely related to $r$. The maximum $V_{E F}$ peak is registered for $r$ between 0.1 and 0.2 , considered a critical description for real dams. The presence of downstream water depth also modifies the dam-break wave frontal shape and types of wave break features. Previously published classifications of the moving wave based on those features are now expanded with a first tested $r=0.8$ in which no jet was identified (undulated movement).
\end{abstract}

Keywords: Dam-break wave; Wave shape; Wave break; Physical modeling.

\section{RESUMO}

Os estágios iniciais da onda oriunda da ruptura instantânea de uma barragem são avaliados espacial e temporalmente, através de 36 experimentos físicos. Diferentes condições foram testadas, variando as profundidades de água a jusante $(J)$, a montante $(M)$ e sua proporção $(r)$. Dois parâmetros adimensionais são propostos - altura efetiva $\left(H_{E F}\right)$ e velocidade efetiva $\left(V_{E F}\right)$ - para avaliar a altura da lâmina d'água e os picos de velocidade ao longo do desenvolvimento da onda de ruptura de barragem. A altura máxima da onda é estimada em função de $r$, enquanto $H_{E F}$ está inversamente relacionada a $r$. O pico máximo de $V_{E F}$ é registrado para $r$ entre 0,1 e 0,2 , considerada uma situação crítica para barragens reais. A presença de água a jusante também modifica o formato da onda e os tipos de quebra dessa onda. As classificações publicadas anteriormente da onda em movimento, com base nessas características, são expandidas com um primeiro $r$ testado $(r=0,8)$ para o qual nenhum jato foi identificado (movimento ondulado).

Palavras-chave: Onda de ruptura de barragem; Formato da onda; Quebra da onda; Modelagem física. 


\section{INTRODUCTION}

The dam-break wave is described as an unsteady translatory wave, moving on the water free surface, with net mass transport in the direction of wave movement (Le Méhauté, 1976). Strictly, a translatory wave with steep front is called a surge. In addition, a positive wave has water depth behind the wave (as defined by the direction of translation) higher than the undisturbed flow depth. Conversely, in a negative wave the flow depth behind the wave is lower than in the undisturbed flow depth (Chaudhry, 2008). In initial stages, an unsteady varied flow occurs instantaneously. A violent and turbulent spray of water escapes (Wu, 2014), causing an instantaneous adjustment of the pressure field because the fluid is incompressible. This adjustment of the pressure field causes the resulting unsteady motion, eventually producing a bore as observed experimentally (Stansby et al., 1998). The mass of water flows horizontally (like a jet) under gravity, representing the non-Boussinesq limit in which air is the fluid of smallest density (Mariño \& Thomas, 2011).

An experimental approach was used to understand and visualize the initial stages of formation and development of the dam-break wave under controlled conditions. Typically, a twodimensional setup is idealized, with a barrier (dam) being instantly removed between two standing bodies of water, each with initial different water depths (or in some cases dry downstream), upon a horizontal surface (Chanson, 2006). After this point, the dambreak wave was fully characterized in terms of geometries and hydrodynamic properties. Actually, dam-break is not instantaneous, because the break occurs gradually as a consequence of complex interactions between water and soil (material forming the dam) (Stansby et al., 1998).

A better understanding is of outmost significance for all aspects of the dynamics, particularly the initial stages of the dambreak wave. The classification, generation and propagation of dambreak waves define the evolution of the phenomenon, principally the impacts and consequences of the flow in downstream locations. Over the years, experimental observations and measurements aided the characterization of flows in their initial stages and the temporal and spatial evolution, including jet types, wave height, water level changes (peaks), and the relevant kinematic parameters such as wave front velocity, acceleration or deceleration (Stansby et al., 1998; Jánosi et al., 2004; Bukreev \& Gusev, 2005; Leal et al., 2006; Soares-Frazão \& Zech, 2007, 2008; Ozmen-Cagatay \& Kocaman, 2010; Khankandi et al., 2012; Hsu et al., 2014; Elkholy et al., 2016; Liu \& Liu, 2017; Espartel, 2015; Stolle et al., 2019; Von Häfen et al., 2019). However, experimental data are lacking in the literature combining jet flows and break shapes, including maximum values of dam-break waves with spatial and temporal evolution.

The relationship between the upstream $(M)$ and downstream $(J)$ water depths of the dam, represented by a non-dimensional parameter $r\left(J M^{-1}\right)$ has been taken into account. Stansby et al. (1998) and Bukreev \& Gusev (2005) classified the positive wave front as a horizontal jet $(r=0)$, transitional jet $(r=0.45)$ or mushroom jet $(r=0.1)$, together with two forms of breaks for the dam-break wave: either an abrupt and violent plunging or a unstable tube (spilling) (Le Méhauté, 1976; Stansby et al., 1998; James, 2016). However, the changes caused on the dam-break wave related to a complete range of $r$ values is not fully available.
We aim to identify the geometric (wave height, jet and break type) and kinematic (maximum velocity) features characteristic of the initial stages of development of the dam-break wave using a simplified physical model of an instantaneous dam-break. Different simulations varied the non-dimensional parameter $r$. Two nondimensional parameters concerning the gain in water depth and velocity peak along the dam-break wave evolution are proposed. The experimental values of $r$ selected intend to represent realistic conditions for prototype dams, thus generating initial conditions for the waves (in their dimensionless form) that can be confidently up-scaled to field cases. These conditions help refine the primary classification of a dam, either before or after execution and thus guide the needed preventive measures. Equally, the use of a model of instantaneous barrier removal generates a key simulation, because it presents the highest velocity peaks in the development of the dam-break wave, which is fundamental for practical applications for engineering design and dam operation (Stansby et al., 1998).

\section{EXPERIMENTAL APPARATUS}

The experiments were performed at Núcleo de Estudos em Correntes de Densidade (Necod), Instituto de Pesquisas Hidráulicas (IPH), Universidade Federal do Rio Grande do Sul (UFRGS), in Porto Alegre - Brazil. A horizontal rectangular acrylic flume was used with $6.0 \mathrm{~m}$ length, $0.24 \mathrm{~m}$ width and $0.49 \mathrm{~m}$ depth. The dam is represented by a $0.03 \mathrm{~m}$-thick, flat rectangular metal plate measuring $0.24 \times 0.60 \mathrm{~m}$, located $0.71 \mathrm{~m}$ from the upstream end of the flume. Horizontal and vertical rulers were attached to the flume walls for reference. The instantaneous dam-break was performed by the up-vertical movement of the dam plate, using a weight, rope and pulley system (Ozmen-Cagatay \& Kocaman, 2010; Duarte et al., 2011; LaRocque et al., 2013; Elkholy et al., 2016; Espartel, 2019). The pulley was installed $3.20 \mathrm{~m}$ above the bottom of the channel. To trigger the movement, a $17.5 \mathrm{~kg}$ sand bag was free-fall released at a height of $3.0 \mathrm{~m}$. When the dam plate started to move, water flowed from the upstream reservoir into the downstream flume, creating the dam-break wave. The efficiency system was measured by comparing the opening time $\left(t_{\text {open }}\right)$ with the criteria established by Vischer \& Hager (1998). These authors pointed out that a dam break is considered instantaneous when $t_{\text {open }}$ satisfies the following relation:

$$
t_{\text {open }} \leq 1.25 \sqrt{\mathrm{Mg}^{-1}}
$$

where $M$ is the upstream water depth and $\mathrm{g}$ is the gravitational acceleration. For example, the opening time observed for the maximum upstream water depth tested, $M=0.4 \mathrm{~m}$, was $0.1 \mathrm{sec}$, which is below the maximum opening time of $0.25 \mathrm{sec}$ for this specific case, as given by Equation 1. We point out that other systems used and reported in the literature were more efficient and faster, for example the pneumatic pressurization system used by Khankandi et al. (2012), Wu (2014) and Liu \& Liu (2017).

Two high-speed cameras (Apple Ipad Pro) were used to record images of the experiments at a rate of 240 frames per second. Both cameras were positioned at $1.05 \mathrm{~m}$ from the lateral wall of the flume, and separated laterally by $0.66 \mathrm{~m}$. The total distance covered by the cameras was $1.55 \mathrm{~m}$ from the dam plate position. Figure 1 presents a sketch of the experimental setup used. 


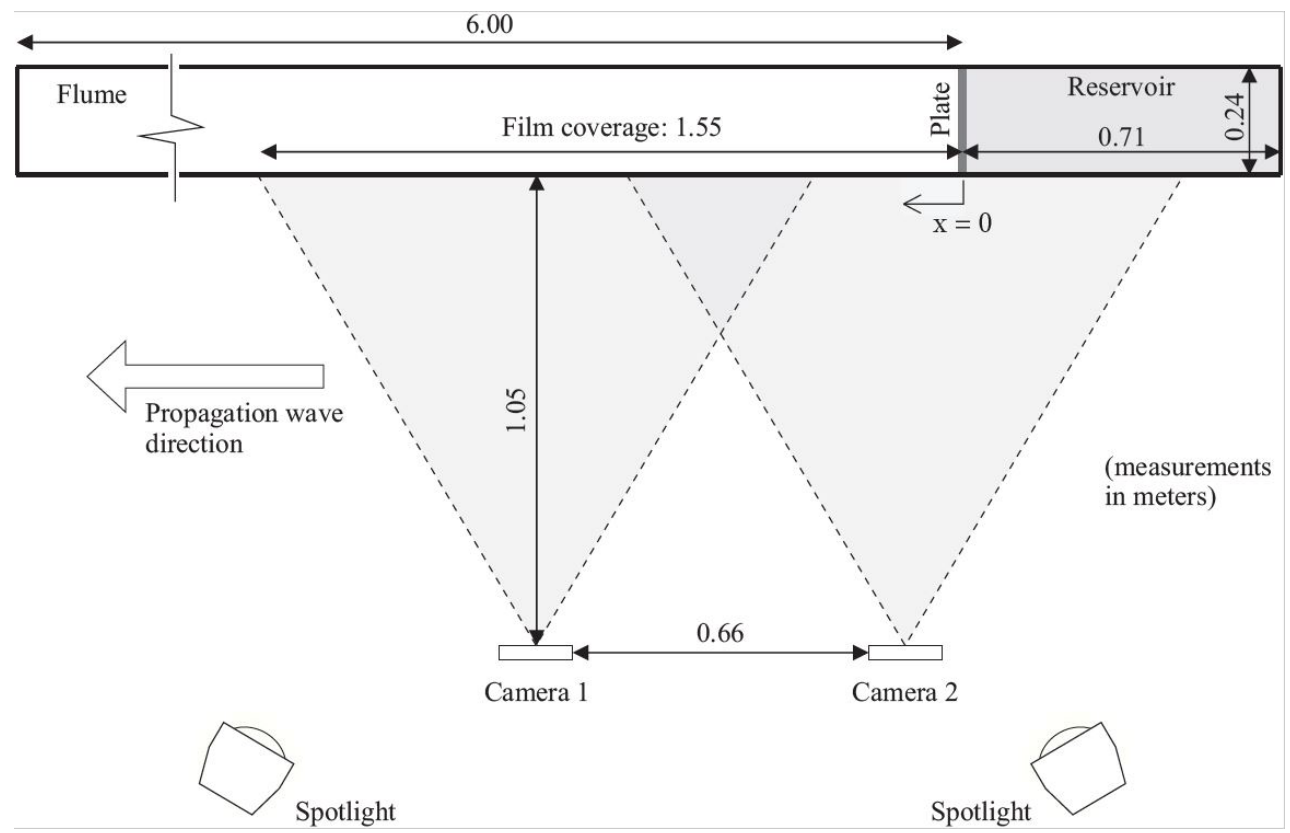

Figure 1. Schematic sketch of the experimental setup (dam-break wave propagates from right to left).

\section{Experimental planning}

Twelve different scenarios of simulations were tested by combining different upstream water levels $(M)$ of the reservoir $(0.10,0.20$ and $0.40 \mathrm{~m})$, and downstream water levels $(J)$ in the flume $(0,0.02,0.04$ and $0.08 \mathrm{~m})$. As mentioned, the ratio $(r)$ of downstream $(J)$ and upstream $(M)$ water depths was used as the scaling, non-dimensional parameter (Equation 2) (Stansby et al., 1998; Jánosi et al., 2004; Bukreev \& Gusev, 2005; Hsu et al., 2014):

$$
r=J M^{-1}
$$

Six values of $r$ were tested, starting from 0.8 and decreasing to the case of downstream dry flume, where $r$ is zero $(0 ; 0.05 ; 0.1$; $0.2 ; 0.4 ; 0.8)$. Moreover, three repetitions were performed for each simulation, totaling 36 experiments (Table 1 ).

\section{Experimental procedure and data processing}

The preparation of the experiments began by placing the dam plate into the flume at the $0.71 \mathrm{~m}$ position, and filling the flume from downstream (except in dry simulations). Color dye (green or red) was used to distinguish upstream and downstream water bodies, and later, the wave front from the standing water. Water temperature was recorded in all cases. Each experimental run was started by triggering simultaneously the dam (plate) removal mechanism and the high-speed camera recording system. Cameras recorded the travel of the generated waves along $1.55 \mathrm{~m}$ of the flume.

After each experiment, the video of recorded dam-break wave was processed and individual digital images (frames) were extracted using the Virtualdub software. Then, we could identify the various stages of wave breaking using the edge detection tool of the Plot Digitizer software. This tool displays an image on a
Cartesian plane, allowing the user to manually detect the contour of the wave, by marking points, which are then exported to spreadsheets. This methodology is analogous to Ozmen-Cagatay \& Kocaman (2010). Pictures of the footage were analyzed each time the wave reached distances of $0.10,0.20,0.30,0.40,0.50$ and $0.60 \mathrm{~m}$ along the flume. Proper calibration of the images to obtain positioning and geometric parameters of the waves was made possible by using the flume-attached measuring rulers (see Figure 2 for an example).

\section{Geometric parameters}

We measured the maximum height $\left(H_{\text {MAX }}\right)$ of the dambreak wave (Figure 2 - dashed line) by using the digital image technique processing. A non-dimensional parameter is proposed, called effective height $\left(H_{E F}\right)-$ Equation 3 . This parameter refers to the maximum height gain caused by the dam-break wave, and represented by the difference between maximum wave height $\left(H_{M A X}\right)$ and the initial downstream water depth $(J)$, in relation to $J$.

$H_{E F}=\left(H_{M A X}-J\right) J^{-1}$

\section{Kinematic parameters}

The study of initial stages of the dam-break wave velocity was made through inspection of $0.05 \mathrm{~m}$-long sections for the first $0.20 \mathrm{~m}$ of the flume downstream section, and then using $0.20 \mathrm{~m}$-long sections for the next $1.00 \mathrm{~m}$ (i.e., from 0.20 to $1.20 \mathrm{~m}$ from the dam plate). The wave front velocity was measured considering the distance travelled by the wave, obtained from the flume ruler, divided by the time, obtained from the corresponding readings of labelled camera frames at the measured point, for each 
Table 1. Experimental planning with conditions tested. Labelling of runs: e.g. M40 indicates $0.40 \mathrm{~m}$ of upstream water depth (reservoir); J8 represents $0.08 \mathrm{~m}$ of downstream water depth (flume); \# 3 indicates repetition run for a given setting.

\begin{tabular}{|c|c|c|c|c|c|c|c|c|c|}
\hline $\mathbf{N \#}$ & $\begin{array}{c}M \\
(\mathrm{~cm})\end{array}$ & $\frac{J}{(\mathrm{~cm})}$ & $\begin{array}{c}r \\
(-)\end{array}$ & Code & $\mathbf{N \#}$ & $\begin{array}{c}M \\
(\mathrm{~cm})\end{array}$ & $\frac{J}{(\mathrm{~cm})}$ & $\begin{array}{c}r \\
(-)\end{array}$ & Code \\
\hline 1 & 10 & 0 & 0.00 & M10-J0-1 & 19 & 20 & 4 & 0.20 & M20-J4-1 \\
\hline 2 & & & & M10-J0-2 & 20 & & & & M20-J4-2 \\
\hline 3 & & & & M10-J0-3 & 21 & & & & M20-J4-3 \\
\hline 4 & & 2 & 0.20 & M10-J2-1 & 22 & & 8 & 0.40 & M20-J8-1 \\
\hline 5 & & & & M10-J2-2 & 23 & & & & M20-J8-2 \\
\hline 6 & & & & M10-J2-3 & 24 & & & & M20-J8-3 \\
\hline 7 & & 4 & 0.40 & M10-J4-1 & 25 & 40 & 0 & 0.00 & M40-J0-1 \\
\hline 8 & & & & M10-J4-2 & 26 & & & & M40-J0-2 \\
\hline 9 & & & & M10-J4-3 & 27 & & & & M40-J0-3 \\
\hline 10 & & 8 & 0.80 & M10-J8-1 & 28 & & 2 & 0.05 & M40-J2-1 \\
\hline 11 & & & & M10-J8-2 & 29 & & & & M40-J2-2 \\
\hline 12 & & & & M10-J8-3 & 30 & & & & M40-J2-3 \\
\hline 13 & 20 & 0 & 0.00 & M20-J0-1 & 31 & & 4 & 0.10 & M40-J4-1 \\
\hline 14 & & & & M20-J0-2 & 32 & & & & M40-J4-2 \\
\hline 15 & & & & M20-J0-3 & 33 & & & & M40-J4-3 \\
\hline 16 & & 2 & 0.10 & M20-J2-1 & 34 & & 8 & 0.20 & M40-J8-1 \\
\hline 17 & & & & M20-J2-2 & 35 & & & & M40-J8-2 \\
\hline 18 & & & & M20-J2-3 & 36 & & & & M40-J8-3 \\
\hline
\end{tabular}

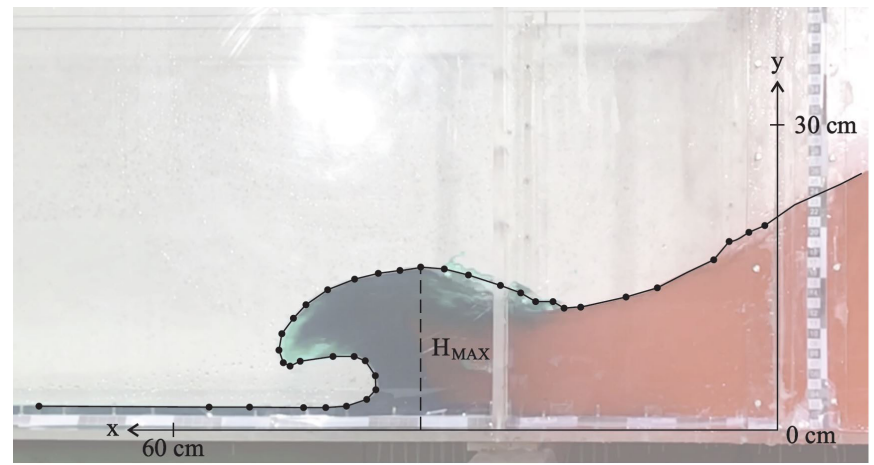

Figure 2. Example of Plot Digitizer software application on the dam break images. The user manually picks the edge points (black dotted line) of the wave and the software converts into X and $\mathrm{Y}$ values. The dashed line shows the maximum wave height of the dam break wave.

section. The mean wave velocity $\left(V_{M E D}\right)$ is defined by the medium value of all sections and the maximum wave velocity $\left(V_{\text {MAX }}\right)$ is the maximum value among all sections.

To evaluate the maximum velocity $\left(V_{\text {MAX }}\right)$, a non-dimensional parameter called effective velocity $\left(V_{E F}\right)$ is proposed - Equation 4. This parameter refers to the maximum velocity gain $\left(V_{M A X}-V_{M E D}\right)$ in relation to the mean velocity of the dam break wave $\left(V_{\text {MED }}\right)$,

$V_{E F}=\left(V_{M A X}-V_{M E D}\right) V_{M E D}^{-1}$

\section{RESULTS}

\section{Jet type and wave break shape analysis}

For all simulated scenarios, i.e., different values of $r$, a qualitative analysis of sequences of digital images from the initial stages of the dam-break wave was performed at less than $1 \mathrm{sec}$ interval. Table 2 summarizes all geometric and kinematic parameters measured and used in this work (the parameters for M10-J8 run were not presented because of the observed undulation movement).

The observed flows were classified by shape - jet type and the wave front break shape, if present. Table 3 presents it as a function of parameter $r$, and Figure 3 shows some images of the wave developing over time and space.

Experiments with dry downstream, i.e., no initial water depth in flume or $r=0$ (see Figure 3a), show a jet type that was independent of water level of the reservoir $(M)$. The first stage of the dam-break wave formed a thicker tip region (frontal) in a horizontal jet (Figure 3b) followed by a thinner column of water (Figure 3c). For lower values of upstream water depth $M$ (e.g., M10), this difference was less evident. Next, the thicker wave tip front moved faster and thus created a longer horizontal shape (Figure 3d and Figure 3e). After reaching a distance of approximately 2.5 times the value of water level $M$, the tip region and the subsequent wave showed similar height (Figure $3 \mathrm{e}$ and Figure $3 \mathrm{f}$ ). For this value of $r$, no wave break shape was observed in the experiments.

For the dam-break wave generated by experiments in which $r=0.40$, a jet type of the flow was classified as a transition jet and the wave break shape as spilling break (Figure $3 g$ to Figure 31). The development of the dam-break wave showed that the wave front advanced underneath the downstream water surface, then raised to acquire the crest shape which became unstable (Figure 3h) and spilled. As a result, the local instability propagated downstream (Figure $3 \mathrm{i}$ to $3 \mathrm{k}$ ). The wave energy was slowly dissipated downstream, creating a smoother wave (Figure 31) without blistering. The maximum height and distance downstream reached by the experimental waves increased with upstream water depth $M$. As an example, the experiment M10-J4 reached maximum height of $0.10 \mathrm{~m}$ and breaking at $0.30 \mathrm{~m}$ distant from the dam 
Table 2. Geometry and kinematic parameters measured for all runs.

\begin{tabular}{|c|c|c|c|c|c|c|c|c|c|c|}
\hline \multirow{2}{*}{$M$} & \multirow{2}{*}{$J$} & \multirow{2}{*}{ Run } & \multirow{2}{*}{$r$} & \multirow{2}{*}{$H_{M A X}$} & \multirow{2}{*}{$\mathbf{H}_{\mathrm{EF}}$} & \multirow{2}{*}{$V_{M E D}$} & \multirow{2}{*}{$V_{M A X}$} & \multirow{2}{*}{$V_{E F}$} & \multicolumn{2}{|c|}{ Peak Location X } \\
\hline & & & & & & & & & $H_{M A X}$ & $V_{M A X}$ \\
\hline (m) & (m) & & $(-)$ & (m) & (m) & $\left(\mathrm{m} \mathrm{s}^{-1}\right)$ & $\left(\mathrm{m} \mathrm{s}^{-1}\right)$ & $\left(\mathrm{m} \mathrm{s}^{-1}\right)$ & (m) & (m) \\
\hline 0.10 & 0.00 & M10-J0 & 0.00 & 0.039 & $\infty$ & 1.06 & 1.30 & 0.22 & 0.10 & 0.40 \\
\hline 0.10 & 0.02 & M10-J2 & 0.20 & 0.064 & 2.22 & 1.01 & 1.18 & 0.17 & 0.20 & 0.40 \\
\hline 0.10 & 0.04 & M10-J4 & 0.40 & 0.080 & 1.00 & 0.88 & 1.08 & 0.23 & 0.20 & 0.40 \\
\hline 0.20 & 0.00 & M20-J0 & 0.00 & 0.077 & $\infty$ & 1.73 & 2.11 & 0.22 & 0.40 & 0.60 \\
\hline 0.20 & 0.02 & M20-J2 & 0.10 & 0.102 & 4.08 & 1.68 & 2.15 & 0.28 & 0.40 & 0.60 \\
\hline 0.20 & 0.04 & M20-J4 & 0.20 & 0.137 & 2.42 & 1.46 & 1.93 & 0.32 & 0.30 & 0.80 \\
\hline 0.20 & 0.08 & M20-J8 & 0.40 & 0.166 & 1.07 & 1.36 & 1.74 & 0.28 & 0.50 & 1.20 \\
\hline 0.40 & 0.00 & M40-J0 & 0.00 & 0.119 & $\infty$ & 2.24 & 2.83 & 0.27 & 0.60 & 1.20 \\
\hline 0.40 & 0.02 & M40-J2 & 0.05 & 0.167 & 7.33 & 2.41 & 3.17 & 0.32 & 0.60 & 0.80 \\
\hline 0.40 & 0.04 & M40-J4 & 0.10 & 0.220 & 4.49 & 2.24 & 3.52 & 0.57 & 0.60 & 1.20 \\
\hline 0.40 & 0.08 & M40-J8 & 0.20 & 0.272 & 2.40 & 1.95 & 2.62 & 0.35 & 0.60 & 1.20 \\
\hline
\end{tabular}

Table 3. Jet type and wave-break shape classification as a function of $r$.

\begin{tabular}{|c|c|c|c|c|c|}
\hline $\begin{array}{c}r \\
(-)\end{array}$ & Code & $\begin{array}{c}M \\
(\mathrm{~cm})\end{array}$ & $\begin{array}{c}J \\
(\mathrm{~cm})\end{array}$ & Jet Type & Break Shape \\
\hline 0.80 & M10-J8 & 10 & 8 & Undulation movement & No Break \\
\hline \multirow{3}{*}{0.40} & M20-J8 & 20 & 8 & \multirow{3}{*}{ Transition Jet } & \multirow{3}{*}{ Spilling Break } \\
\hline & M10-J4 & 10 & 4 & & \\
\hline & M40-J8 & 40 & 8 & & \\
\hline \multirow[t]{2}{*}{0.20} & M20-J4 & 20 & 4 & \multirow{6}{*}{ Mushroom Jet } & \multirow{6}{*}{ Plunging Break } \\
\hline & M10-J2 & 10 & 2 & & \\
\hline \multirow{2}{*}{0.10} & M40-J4 & 40 & 4 & & \\
\hline & M20-J2 & 20 & 2 & & \\
\hline \multirow[t]{2}{*}{0.05} & M40-J2 & 40 & 2 & & \\
\hline & M40-J0 & 40 & 0 & & \\
\hline \multirow[t]{2}{*}{0.00} & M20-J0 & 20 & 0 & Horizontal Jet & No Break \\
\hline & M10-J0 & 10 & 0 & & \\
\hline
\end{tabular}

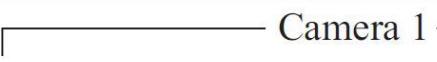

(a) $\mathrm{t}=0.00 \mathrm{~s}$

M40-J0

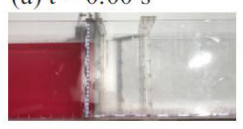

(b) $\mathrm{t}=0.14 \mathrm{~s}$

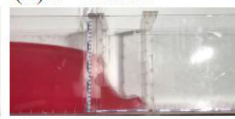

(c) $\mathrm{t}=0.32 \mathrm{~s}$

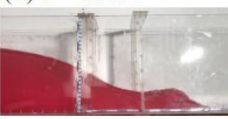

(d) $\mathrm{t}=0.32 \mathrm{~s}$
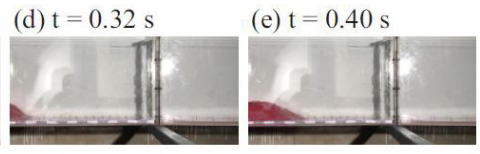

(f) $\mathrm{t}=0.55 \mathrm{~s}$

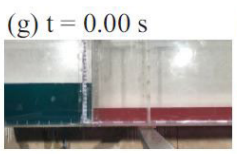

(h) $\mathrm{t}=0.25 \mathrm{~s}$

M20-J8
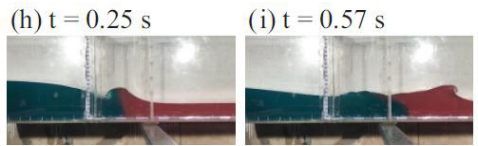

(j) $\mathrm{t}=0.57 \mathrm{~s}$
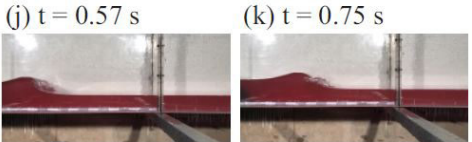

(m) $\mathrm{t}=0.00 \mathrm{~s}$

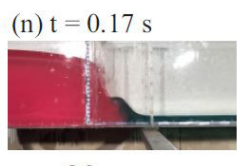

(o) $\mathrm{t}=0.39 \mathrm{~s}$

(p) $\mathrm{t}=0.39 \mathrm{~s}$

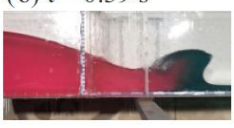

$\mathrm{x}=60 \mathrm{~cm}$

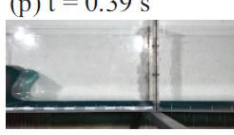

$\mathrm{x}=60 \mathrm{~cm}$

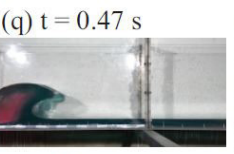

$\mathrm{x}=80 \mathrm{~cm}$

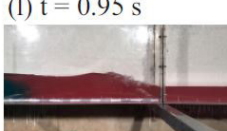

$r=0.40$

spilling break

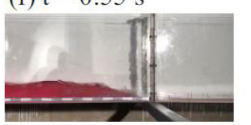

$r=0.00$ horizontal jet no break

(r) $\mathrm{t}=0.61 \mathrm{~s}$

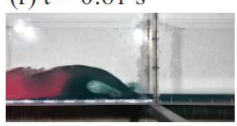

$r=0.05$ plunging break

Figure 3. Sequence of images from the initial stages of the dam-break wave, for different $r$ values. Note that the last photo of Camera 1 and the first photo of Camera 2 portray the same instant, so they have the same timing and the same distance $\mathrm{x}$.

plate, while experiment M20-J8 reached the maximum height of $0.16 \mathrm{~m}$ and breaking at $0.60 \mathrm{~m}$.

The experimental runs that simulated values of $0.05 \leq r \leq 0.2$ (Figure $3 \mathrm{~m}$ to $3 \mathrm{r}$ ) generated wave fronts that advanced faster, aided presumably by the presence of an initial downstream water depth (Figure 3n). For these cases, the flow type was classified as mushroom jet followed by a plunging breaking wave (Figure 3o to 3p), as the wave crest steepened (Figure 3q), releasing most of its stored energy and impacting on the downstream standing water surface (Figure 3r). During the development of the plunging breaking wave, four stages were identified: (i) faster upstream to downstream water flow, (ii) vertical water accumulation, (iii) forward projection, and (iv) breakdown, impacting on downstream standing water. In these cases the upstream water level $M$ influenced the distance 
and time of occurrence of plunging breaking wave. For lower values of $M$ (e.g. M10 and M20), the four above-mentioned stages occurred within a distance of $0.60 \mathrm{~m}$. Only the first three stages were identified in some cases (M40-J4), and only one in some others (e.g. M40-J8) in the first $0.20 \mathrm{~m}$ of the flume downstream after the dam plate location.

No experiments were performed for $r$ between 0.2 and 0.4. Nevertheless, Jánosi et al. (2004) commented that a threshold value $r=0.25$ transforms one type of jet flow and break shape into the two here described (mushroom jet and plunging break to transition jet and spilling break). One particularly run produced $r=0.8$ (M10-J8; Table 3), which did not show any notable wave break. In fact, the wave presented just a slight elevation (approximately 1\%) of the water depth downstream ( $($ ). This jet type is classified here as an undulation movement of the wave that propagated downstream.

\section{Geometrical analysis}

The geometric analysis focused on maximum wave heights, associated to the travelled distance of the wave, in the initial moments of the dam-break wave. The distances corresponding to the height peak of the waves were plotted for all experimental runs (Figure 4).

The position of the wave height peak increased with initial values of reservoir water level $M$. For M10 runs, the maximum wave height along the distance was small, nearly negligible. But a slight elevation occurred between the 0.10 and $0.20 \mathrm{~m}$ distance from the dam plate as $J$ increased. M20 runs produced thicker dam-break waves associated with higher values of maximum height peaks. M40 runs reached the maximum wave height at $0.60 \mathrm{~m}$ regardless of the downstream water depth $(J)$. Increase in the downstream water depth $(J)$ enhanced the maximum wave height for all runs. This enhancement was expected when the dam break wave maximum height was added to the downstream water level $J$.

Figure 5 shows a non-dimensional parameter, which is the maximum wave height divided by the difference between $M$ and $J$, in correlation with $r$.
The results plotted in Figure 5 suggest a direct relationship between the non-dimensional maximum wave height with $r$. A linear fit equation $\left(\mathrm{R}^{2}=0.992\right)$ is proposed by Equation 5 :

$H_{M A X} /(M-J)=2.511 r+0.342$

Equation 5 appears applicable for dam-break waves with jet formation from $0 \leq r \leq 0.4$, allowing us to predict the maximum wave height for that particularly range of $r$. Consequently, the experiment with $r=0.8$ (undulation movement) was excluded from this correlation analysis because the experiment did not produce the above mentioned jet types or wave-breaking patterns.

A proposed non-dimensional parameter called effective height - see Equation 3-demonstrates the inverse relation between the breaking wave effective height $\left(\mathrm{H}_{\mathrm{EF}}\right)$ measured as excess of downstream water depth $(J)$ and $r$ (Figure 6).

The effective height relation presents a potential fit trend $\left(\mathrm{R}^{2}=0.99\right)$ related to ratio $r$ (Equation 6$)$.

$H_{E F}=0.437 r^{-0.992}$

Assuming that this relation is scalable, we extrapolate the relation to a prototype (real dam). When a river downstream of a dam has a water level below $10 \%$ of the reservoir depth, a failure might produce a dam-break wave 4 to 7.5 times higher than the normal, steady-state river water depth. On the other hand, the dam-break wave will produce less abrupt water elevations in rivers that have water depths $40 \%$ or more than reservoir water depth.

\section{Kinematic analysis}

The velocity developed by the breaking wave was evaluated at two different flume sections (Figure 7): (1) at the most-upstream, initial section of the flume (about $0.20 \mathrm{~m}$ downstream from the dam plate), and (2) in the flume section located between 0.20 and $1.20 \mathrm{~m}$ from the dam plate section. For the first section, only the experiments with dry downstream water depth produced images from which a wave tip was reliably identified. The velocity data

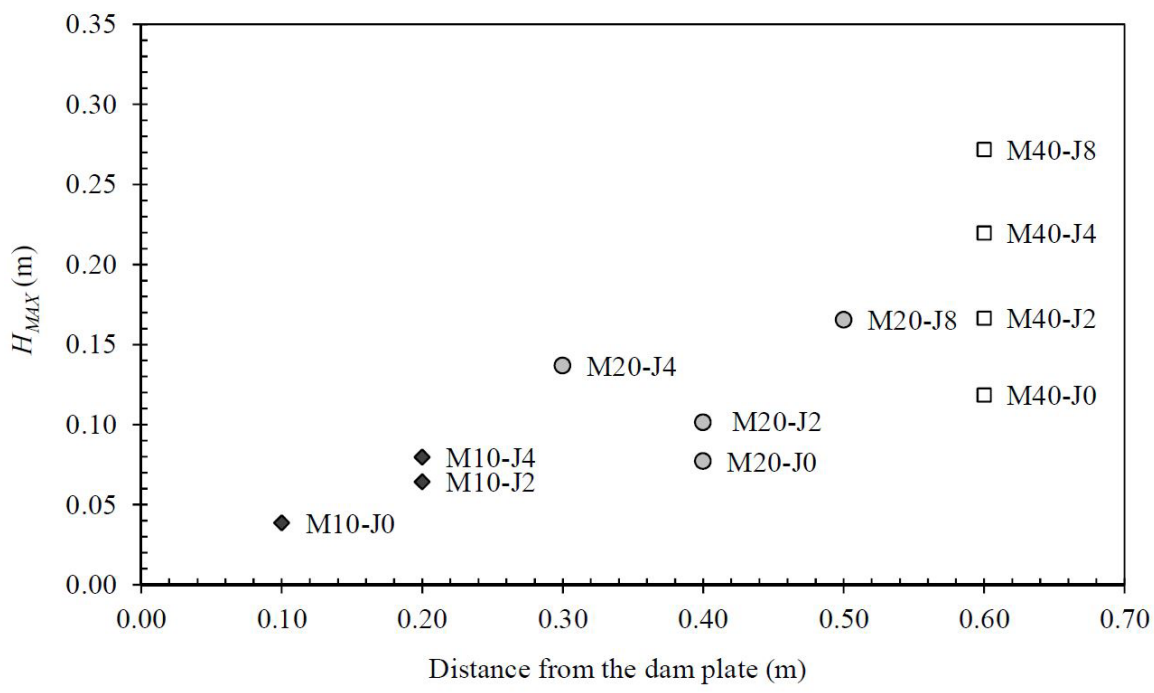

Figure 4. Maximum wave height along the first $0.60 \mathrm{~m}$ of the flume. 


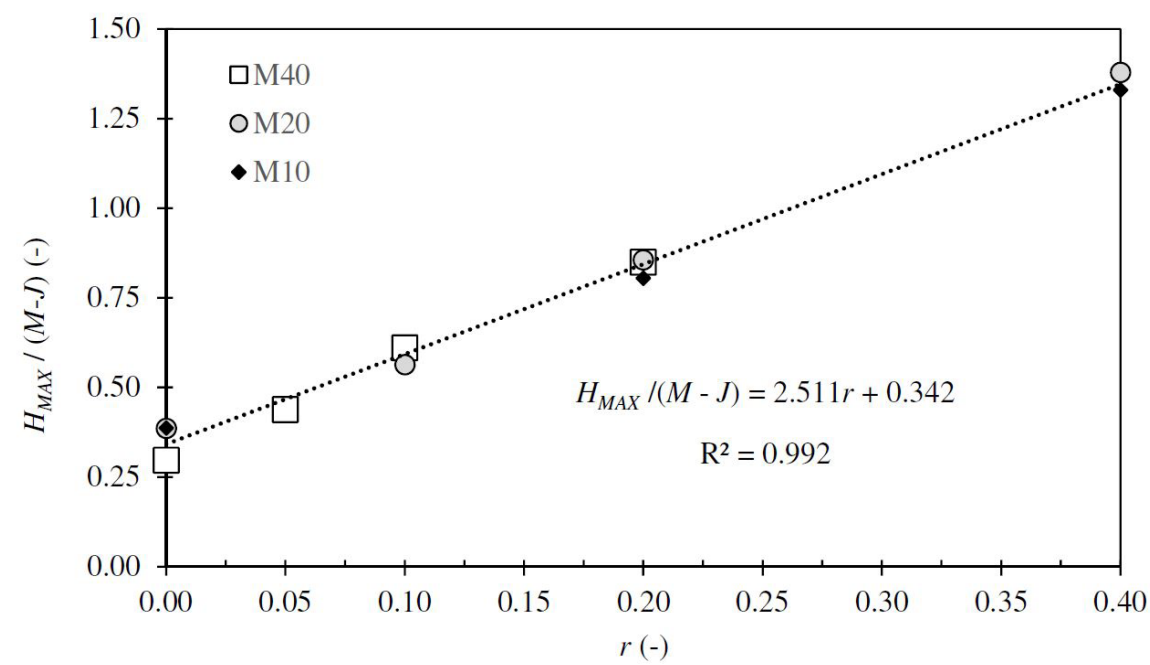

Figure 5. Non-dimensional maximum wave heights $\left(H_{M A X} /[M-J]\right)$, as function of $r$ for all experimental runs.

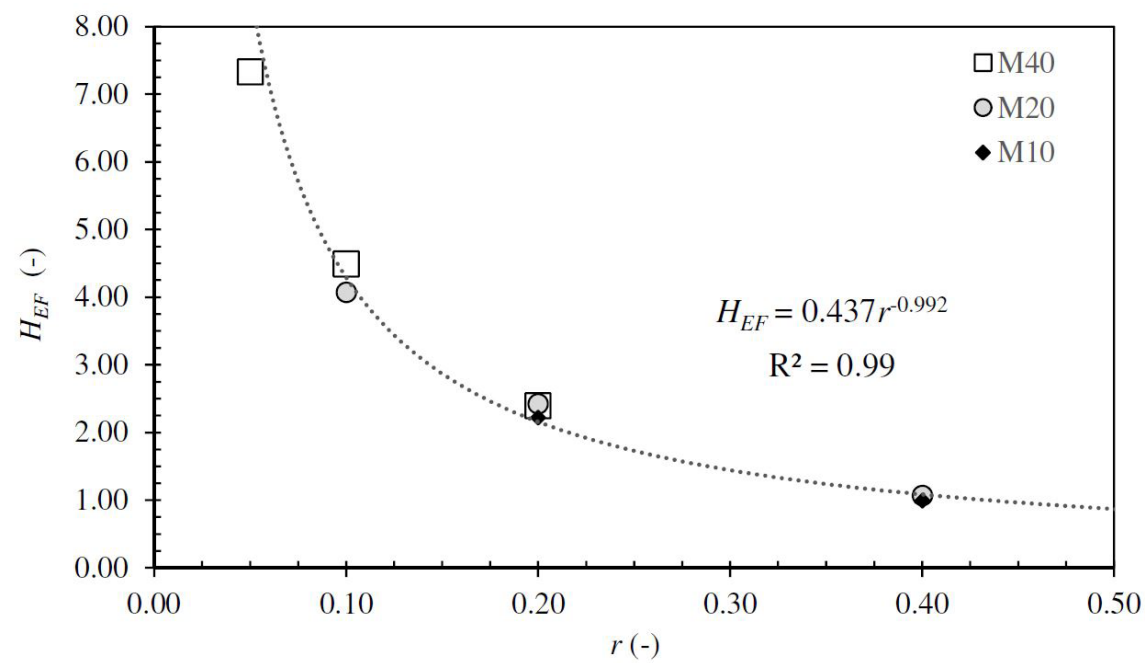

Figure 6. Effective height $\left(H_{E F}\right)$ related to ratio $r$.

for these cases were also correlated with reservoir water level $M$ and downstream water level $J$.

Cycles of accelerations and decelerations were observed during the initial stages of dam- break wave translation. Up to $0.20 \mathrm{~m}$ from the dam plate, two stages were identified for all runs. First, stage (i): section $0.00-0.10 \mathrm{~m}$, which shows an abrupt velocity increase due to the net mass of water released from the reservoir, transforming the potential (reservoir depth) into kinetic energy. Second, stage (ii): section $0.10-0.20 \mathrm{~m}$, showing initial movement of the water column downstream with flow deceleration caused by less-dominant inertial effects exerted by the moving net mass of water and increase in bottom resistance. The experiment with an initial level of $0.40 \mathrm{~m}$ (M40) showed a more drastic velocity reduction between 0.10 and $0.20 \mathrm{~m}$, attributed to an abrupt adjustment of the pressure field from a higher column of water.

For ensuing sections $(>0.20 \mathrm{~m}$ from dam plate), the wave front accelerated for all runs, likely due to a later stage of the water column fall in the reservoir. Deceleration patterns in different positions along the flume were also observed. All M10 group runs showed acceleration up to $0.40 \mathrm{~m}$, deceleration between $0.40 \mathrm{~m}$ and $0.80 \mathrm{~m}$, and re-acceleration between $0.80 \mathrm{~m}$ and $1.20 \mathrm{~m}$. In M20 runs, only two steps were observed, namely acceleration up to $0.60 \mathrm{~m}$ and deceleration following. Although all tests showed a tendency to increase velocity over distance, the waves also developed accelerating and decelerating cycles in the M40 runs.

Velocity magnitudes, particularly during the first acceleration phases, are non-linearly related to the water $\operatorname{depth} M$, as seen by comparing M40 to M10 runs (Figure 7). Wave velocities shows a decreasing trend as $J$ increases, because the existing water column acts as a physical obstacle reducing the velocity of the dam-break wave. However, this behavior was only evidenced for the M10 group. For M20 and M40 runs, the velocity data also present decreasing albeit unclear trends. In few cases, e.g. M20-J2 and M40-J4 both with $r=0.1$, and M40-J2 with $r=0.05$, the maximum velocity (Table 2) was higher than the values for dry downstream flume $(J=0)$. A non-linear relationship was observed between the dam-break wave velocity and the peak location for different reservoir water depths $M$. Experiment M10 peaked at $1.3 \mathrm{~m} \cdot \mathrm{s}^{-1}$ and $0.40 \mathrm{~m}$ from the dam plate, while M20 was around $2.2 \mathrm{~m} \cdot \mathrm{s}^{-1}$ at $0.60 \mathrm{~m}$ from the dam. M40 showed velocity values greater than 

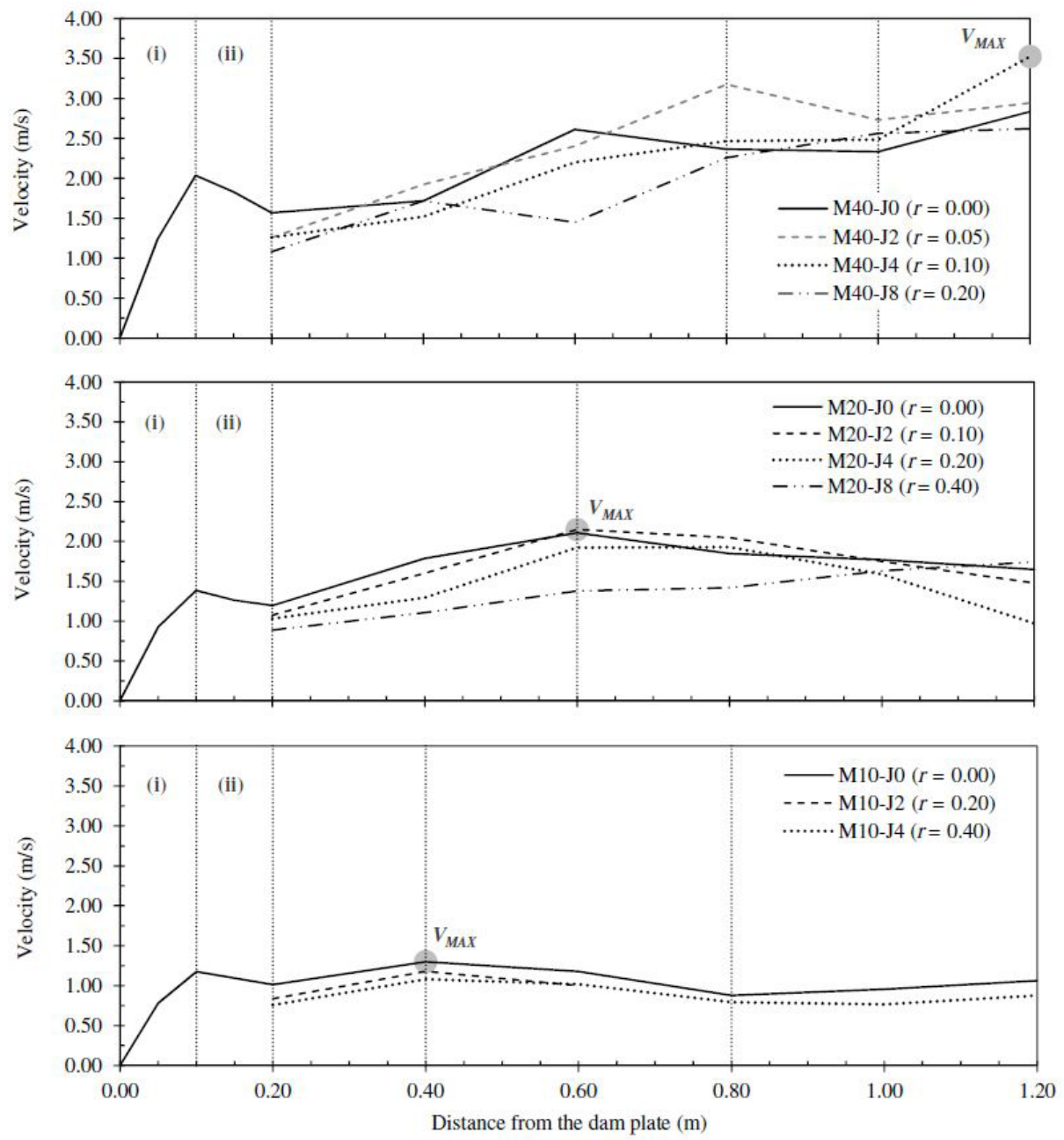

Figure 7. Initial stages of the dam-break wave velocity for all experiments: i) abrupt velocity; ii) flow deceleration.

$3.5 \mathrm{~m} . \mathrm{s}^{-1}$ along the length of $1.20 \mathrm{~m}$, with peaks at 0.80 or $1.20 \mathrm{~m}$ from the plate. The combined effects of water depths $M$ and $J$ (via ratio $r$ ) on the effective velocity $V_{E F}-$ see Equation 4 - are presented in Figure 8.

The effective velocity $\left(V_{E F}\right)$ represents the gain on the maximum wave velocity related with its mean velocity. Results from our experiments show an unlikely behavior in relation to the reservoir water depth $(M)$. Small $M$ values (e.g., M10) keep maximum dam-break waves velocity at $20 \%$ above average. The highest $V_{E F}$ peak was recorded for the dam-break waves generated by higher $M$, e.g., 30\% for M20 and 60\% for M40. These observations suggest a direct relationship between the peaks and reservoir water depth $(M)$. Observations also show that dry downstream water level $(J=0)$ does not correlate in all cases to maximum velocities in the initial stages of development of the dam-break wave. In fact, an effective velocity increases for $r$ between 0.1 and 0.2 , may be associated to the wave formed immediately before the plunging break (Figure $3 \mathrm{n}$ to $3 \mathrm{r}$ ). The column of water flowing as the jet accelerates to raise the water depth creates a crest (Figure 3o), which breaks next. This pattern is less effective in other types of wave breaks and undulations.

The increasing of wave velocity along the distance was not ruled by $r$, but by the dimensional quantities $M$ and $\mathrm{J}$ instead. The waves with the same $r$ present various $V_{E F}$ values. However, considering only the cases of M40 and M20, it is possible to verify that the critical values (peaks) is between $0.1 \leq r \leq 0.2$.

\section{DISCUSSION}

\section{Dam break wave classification}

Our experimental observations indicate that the dambreak wave developed distinctly after different initial conditions were simulated (Table 3). Results are summarized and classified based on flow jet type and water front shape break for different values of $r$. This mentioned classification (Figure 9) expands previous propositions (Stansby et al., 1998; Bukreev \& Gusev, 2005; Jánosi et al., 2004; Ozmen-Cagatay \& Kocaman, 2010; Hsu et al., 2014, Liu \& Liu, 2017). Those experiments used flumes with rectangular cross sections and similar methodology based on images recording as the present study.

Figure 9 includes the different scenarios of upstream and downstream water depth tested in our experiments. Also, Figure 9 shows four distinct flow jet types and break shapes: horizontal jet formation - without breaking, mushroom jet type with plunging break, transition jet with spilling break, and undulated wave motion. Each type is related to a range of $r$ values varying from 


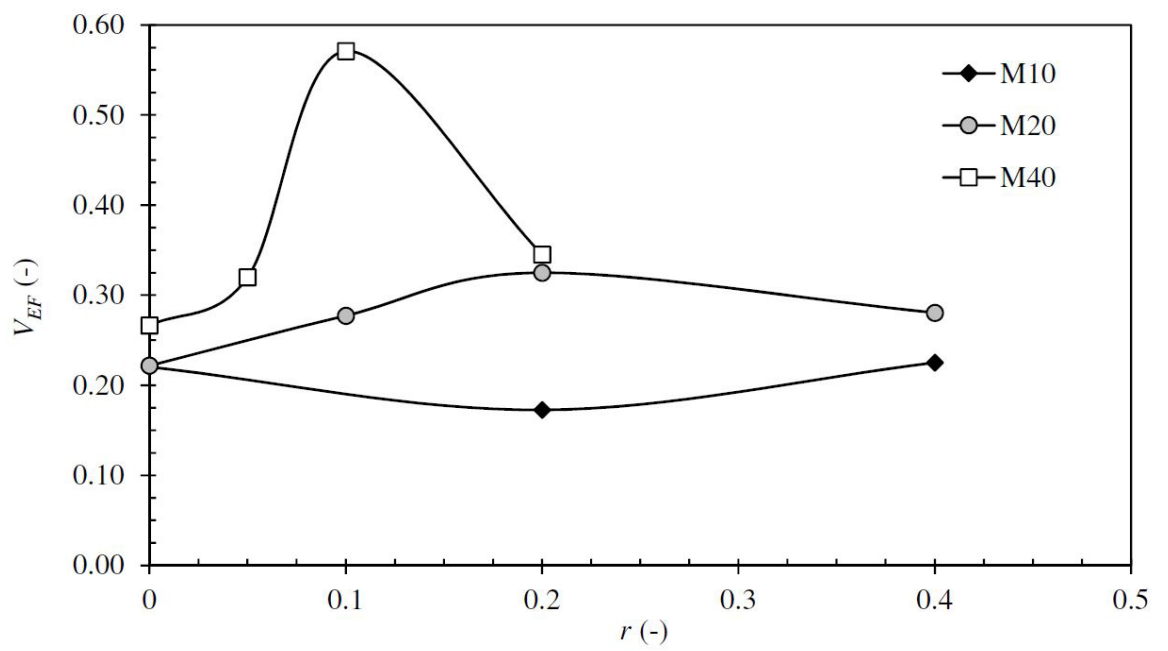

Figure 8. Effective velocity $V_{E F}$ developed by the dam-break waves for each reservoir level (M10, M20 and M40) related to $r$.

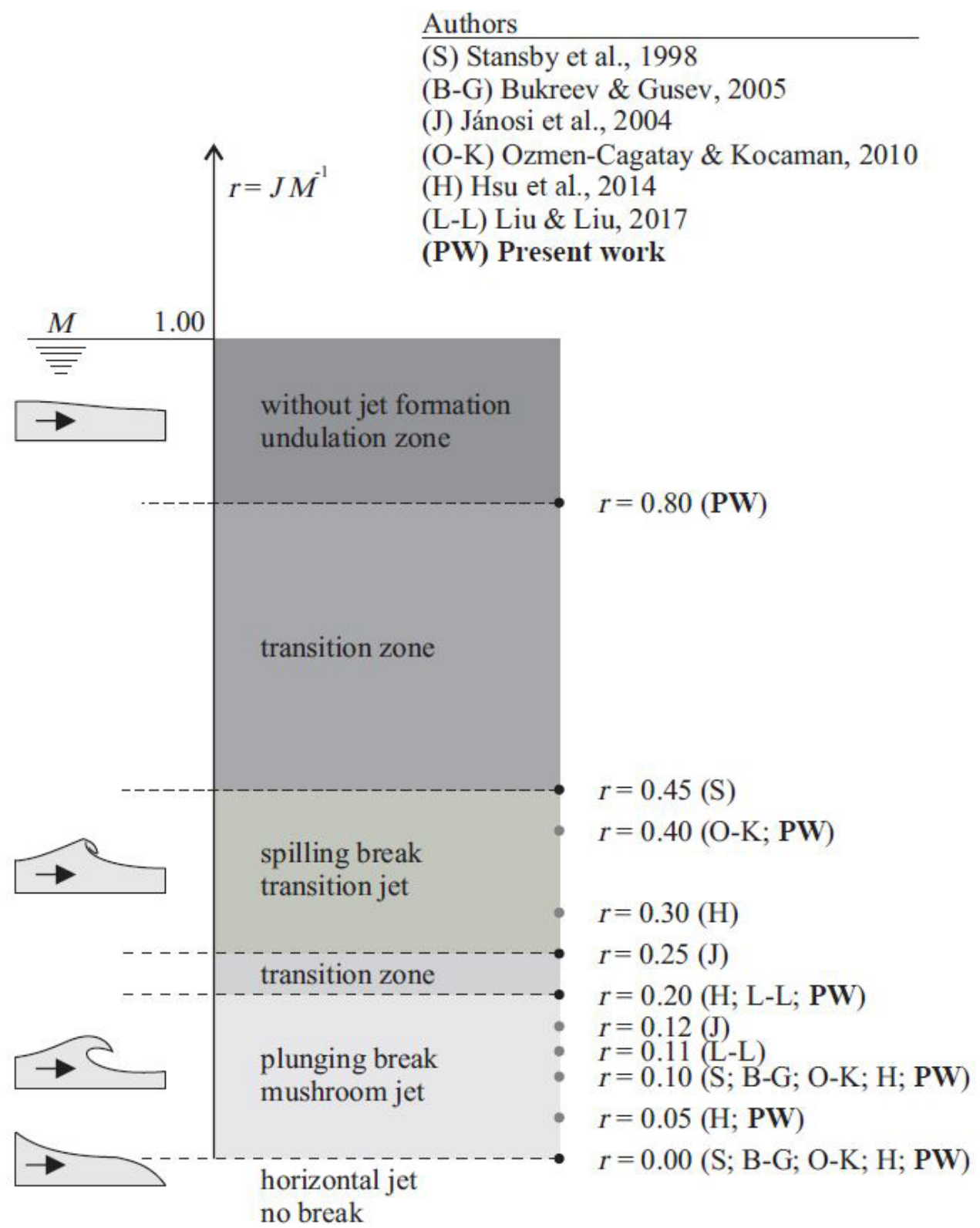

Figure 9. Jet types of dam-break waves and break shape classification as a function of $r$. 
0 to about 1. Previous investigations lack testing in the $r$ interval $0.45-1.00$, which we investigated by doing an experiment with $r=0.8$ and classified $0.45-0.80$ as a transition zone. Lack of testing was motivated by the lower frequency of this particular range of conditions in prototype dams.

Scenarios of $r$ simulated in this work (Figure 9) match with observations from the literature: e.g., Jánosi et al. (2004) suggested $r=0.12$ for plunging break, whereas we found $r=0.10$, similarly to Stansby et al. (1998) and Hsu et al. (2014). A vertical jet is formed during collision of moving and standing water; continuity of the water body is interrupted and air-filled cavities are formed (Bukreev \& Gusev, 2005; and this work). This description characterizes a typical wave break, alternatively plunging or spilling type. Furthermore, the presence of a critical value of $r$ causes the appearance of undulations instead of a vertical jet when $r$ exceeds that undefined limit. We suggest that this value is greater than 0.8 , which corresponds to a first tested $r$ for which no jet was identified.

\section{Dam-break wave kinematic behavior}

The effective height $\left(H_{E F}\right)$ and effective velocity $\left(V_{E F}\right)$ of the dimensionless parameters were cross-correlated to investigate for all runs the trends on the gain in maximum height and velocity for the dam-break wave (Figure 10), except for $r=0,\left(H_{E F}\right.$ tends to infinity; Table 2). In addition, the $r=0.8$ case was estimated (not measured) at $1 \%$ gain in both $H_{E F}$ and $V_{E F}$, because this type of flow minimally affects the stand downstream water.

Figure 10 shows that effective height $\left(H_{E F}\right)$ is directly related to reservoir water depth $M$ and inversely related to $r$ (also Figure 6) for all experiments. The rate of increase of $H_{E F}$ is inversely related to downstream water depth $J$, as smaller $J$ values produced waves with larger $H_{E F}$, i.e., wave with a more destructive height. For instance, the water level reached up to seven times the still downstream water level $(J)$ as seen in $r=0.05$ run.

The effective velocity $\left(V_{E F}\right)$ reached a peak for each initial reservoir condition $M$. This maximum velocity was directly proportional to $M$ and approximately inversely to $r$, and independent of the dam-break wave average velocity. The relationships are due to the initial conditions of $M$ and $J$ (expressed in $r$ ) leading to a gain on the maximum velocity values up to $60 \%$ higher (e.g., M40). The peak $V_{E F}$ values are presented in Figure 10 and the jet type and the break shape relation are presented in Figure 9. A mushroom type and plunging break, i.e., $r$ ranging from 0.1 (M40) to 0.2 (M20) were associated to the higher values of $V_{E F}$ and are potentially the critical scenarios in real dams.

Along the dashed line, $r=0.2, V_{E F}$ increases directly proportional to $M$ and $J$. In other words, as more "bulk volume of water" is involved in the wave (i.e., larger $M$ and larger J), the higher the effective velocity becomes. In terms of engineering, the higher the level of a dam, the more destructive velocity peaks might be produced in relation to the average velocity.

Various authors used different parameters to analyze the wave velocity as a function of the upstream reservoir water depth (M) for dry downstream flumes simulations. Khankandi et al. (2012), LaRocque et al. (2013), Wu (2014), Javadian et al. (2016) showed results based on mean velocity $\left(V_{M E D}\right)$, while Liu \& Liu (2017) used maximum velocity $\left(V_{\text {MAX }}\right)$. We expanded this analysis including the scenario of maximum velocity for $\mathrm{J}>0$ (data from Table 2 and figure 10). The data reported in the literature and our results are shown in Figure 11.

An overall direct correlation between upstream water depth $M$ and both mean and maximum velocity of the wave front is observed in Figure 11. Considering various scenarios of simulation, we adjusted three logarithmic fit lines and the results showed high coefficient of determination $\mathrm{R}^{2}$ (Table 4). These results indicate our experiments can be comparable with the above-mentioned works, despite the fact, various experimental techniques for determination of the wave front velocity were used on these studies. For instance, Khankandi et al. (2012) and Liu \& Liu (2017) used an Acoustic Doppler Velocimeter (ADV), whereas LaRocque et al. (2013) used an Ultrasonic Velocity Profiler (UVP). Possible differences in results still need to be further studied.

The comparison of $J>0$ with dry scenario cases $(J=0)$ demonstrates the impact of $J$ on the maximum velocities, including a direct relationship with the reservoir water depth $M$. The depth increases the maximum velocity in 20\% (although more evident for M20 and M40 runs). A lower M10 value corresponds to dry

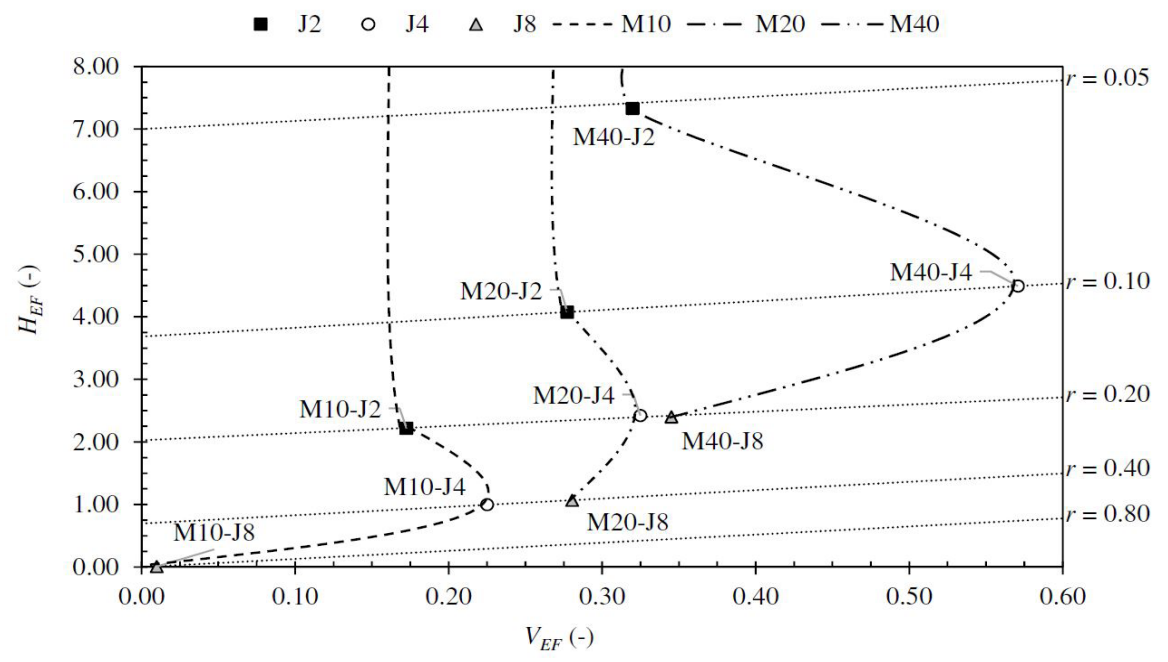

Figure 10. Relationship between $H_{E F}$ and $V_{E F}$. 


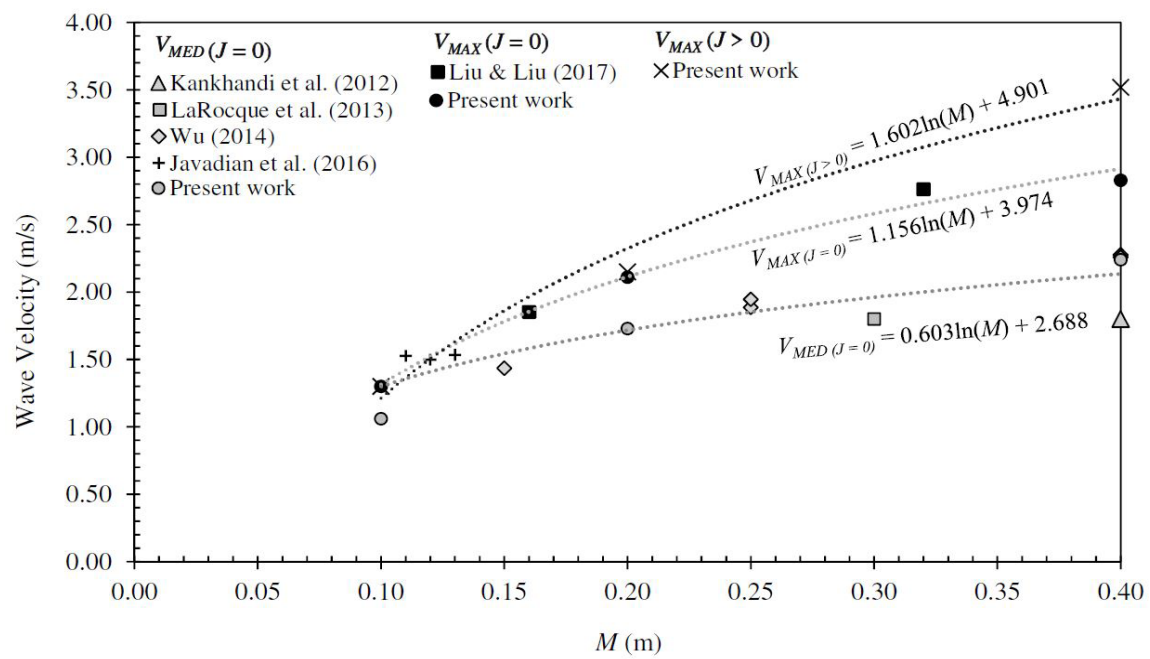

Figure 11. Relationship between maximum and mean dam-break wave velocity and upstream reservoir water depth $(M)$.

Table 4. Logarithmic fit lines for various scenarios of simulation.

\begin{tabular}{cccc}
\hline Condition $J$ & Velocity & Equations & $\mathbf{R}^{2}$ \\
\hline$J=0$ & $V_{M E D}$ & $V_{M E D}=0.603 \cdot \ln (M)+2.688(7)$ & 0.804 \\
$J=0$ & $V_{M A X}$ & $V_{M A X}=1.156 \cdot \ln (M)+3.974(8)$ & 0.989 \\
$J>0$ & $V_{M A X}$ & $V_{M A X}=1.601 \cdot \ln (M)+4.901(9)$ & 0.982 \\
\hline
\end{tabular}

downstream water level $(J)$, and velocity was considered as the maximum value achieved by the dam-break wave.

Alternatively, Hsu et al. (2014) and Liu \& Liu (2017) proposed a non-dimensional velocity $u$, which $V_{M E D}$ is normalized by $(\mathrm{g} M)^{-1 / 2}$ (Equation 10) for comparison between all experiments and scenarios simulated with $J>0$.

$u=V_{M E D}(g M)^{-1 / 2}$

The summarized results using non-dimensional $u$ as a function of $r$ is shown in Figure 12. For comparison, the data of numerical and experimental simulations by Hsu et al. (2014), and Liu \& Liu (2017) are included.

Our experimental results show close agreement with Hsu et al. (2014) and Liu \& Liu (2017), except for $r=0.05$, in which Liu \& Liu (2017) presented a slightly higher value. The difference may be caused by both flume boundary conditions (introducing additional energy dissipation) and measuring techniques. Hsu et al. (2014) uses the non-dimensional velocity to point a change of regime from supercritical $(\mathrm{u}>1)$ to subcritical $(\mathrm{u}<1)$ when $r$ increases beyond 0.2 . In addition, $u$ appears to remain constant in a plateau for $r>0.3$, approximately equivalent to $0.9(\mathrm{~g} M)^{-1 / 2}$.

The dam-break wave propagation process can be described by two different flow regimes (Hsu et al., 2014). During the initial stages after dam break, the wave velocity is higher than a regular downstream water flow depth (e.g., usually natural rivers or artificial channels), producing supercritical flows. However, as resistance increases along propagation distances, the velocity of the propagated wave decreases, the relative importance of the downstream water depth $J$ increases, and the flow becomes subcritical.

The present work corroborates and expands the findings of Hsu et al. (2014), supporting the acceleration and deceleration cycles of the dam-break wave velocity (Espartel, 2015, 2019).
These cycles are explained by the conversion of potential to kinetic energy in the initial stages of the flow and by the subsequent increasing influence of bottom resistance and effects of existing finite water levels downstream. Furthermore, the abrupt transition of flows between $r=0.1$ and 0.2 (Figure 12) is consistent with the maximum effective velocity (Figure 10) for M20 and M40 runs. In other words, the mushroom type of flow and plunging of break can lead either to higher values of velocity or more erodible and destructive flows.

\section{Implications for real dams}

Man-made dams are hydraulic structures used to create water reservoirs devoted to several purposes. The risk of failure and collapse of these structures has decreased with the development of new engineering designs and materials, but the large number of older dams built in the last half-century are approaching their life-span end. These older dams contribute to the finite, non-negligible probability of occurrence of catastrophic failures (Ancey, 2014). Along history, examples of water waves with colossal magnitudes developed after dam breaks: Malpasset (France, 1959), totaling 423 deaths; Banqiao (China, 1975), with more than 171,000 deaths (Montz et al., 2017); Bento Rodrigues Dam (Brazil, 2015), more than 15 deaths; Saddle Dam D (Laos, 2018), with 42 deaths (Olarn et al., 2018) and Brumadinho (Brazil, 2019), with 270 deaths (Lima \& Vale, 2019). All dam failures had catastrophic consequences. Based on that, observations and analyses of the initial stage of dam break is useful for the engineering, dam operation and decision making. The limitations of flume experiments and scaling issues are considerable, requiring further testing and verifications with prototypes.

Our experimental results and analyses suggest a central role for the dimensionless effective height, proposed here as an accurate predictor of downstream water level increases caused by the breaking wave, i.e., the flooding wave evolution in space and time. In fact, the effective height is inversely proportional to $r$. We suggest for prototype dams that this relationship indicates that the more impactful and catastrophic flooding consequences 


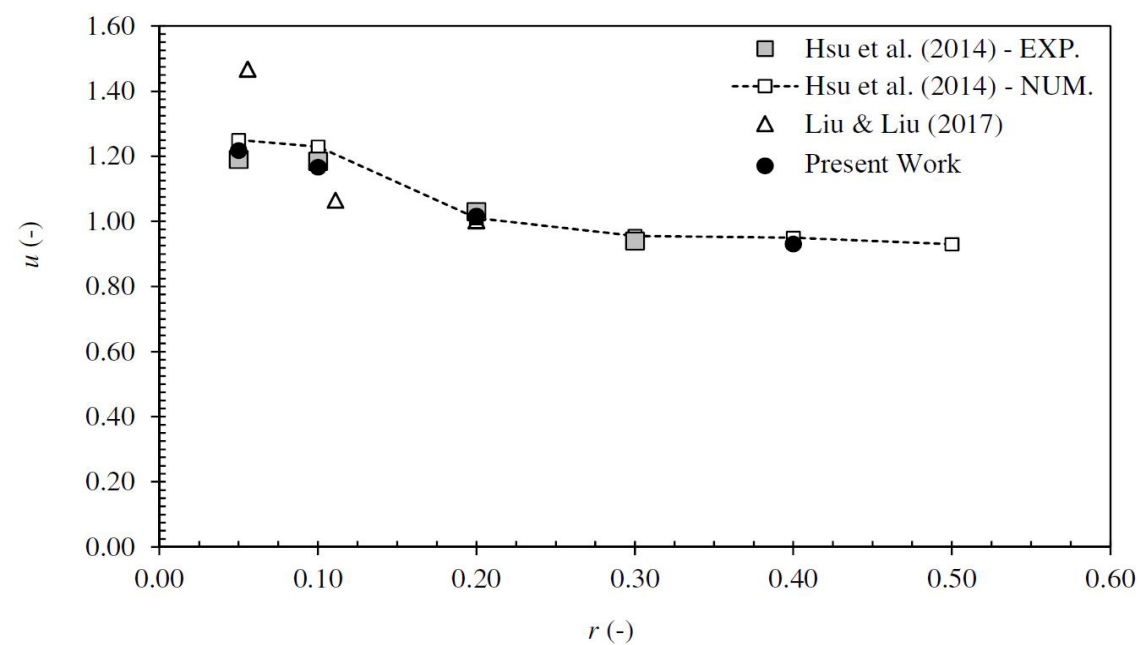

Figure 12. Non-dimensional velocity $u$ as a function of $r$. Adapted from Hsu et al. (2014).

of a dam failure may occur in cases of low water levels $(J)$ in the downstream river in relation to the reservoir water depth $(M)$.

The maximum wave velocity is directly proportional to the reservoir water depth $(M)$ (Figure 7). Considering a prototype dam, all these results suggest that dam-break wave velocities increase as a function of the dam (reservoir) water level (or dam height), potentially leading to catastrophic consequences downstream in case of dam failure. Effective velocity shows that an increment in maximum velocity related to the average velocity reaches a peak value that increases farther from the dam plate as $M$ increases. In real dams, this velocity peak and position indicates isolated location downstream subject to more impactful velocities, i.e., more erosive or destructive values of dam-break waves flowing downstream. In addition, this is a serious concern from a channel stability perspective, because the average velocity causes the climbing above the recommended limit of a regular channel or natural river. In real dams, the initial ratio $r\left(J M^{-1}\right)$ is between 0.1 and 0.2 , so this effect potentially raises the damage levels downstream. These same effects are minimized for dam-break waves with $r>0.8$, because only undulating waves will be present (e.g., Figure 9).

We suggest from our experiments that dam-break waves developed on dry downstream rivers (i.e., $r=0$ ) move faster and have a higher potential for damage and catastrophic flooding for low values of $M$. As $M$ increases to ratios of $r$ between 0.1 and 0.2 , the plunging waves (mushroom-like flows) reach higher heights and maximum velocities, promoting supercritical flows (Figure 12) compared with downstream river or channel water depths.

Locations downstream of dams are often places chosen for population developments, farming, or industrial activities. Effective warning systems are critical for this type of situation, because rising of water level is dangerous and impacts human lives. In contrast, dam-break waves with $r>0.3$ develop slower velocity and subcritical flow, occurring in general in rivers with an existing, relative high water depth.

\section{CONCLUSION}

Based on experimental results presented here, we conclude that dam-break waves simulated for various combinations of upstream and downstream water levels $\left(r=J M^{-1}\right)$ generated different behaviors of flow jet types and wave shape break. Our results support and expand an existing, previously reported classification; we first tested a value for undulated movement $(r$ approximately 0.8 ). However, further studies considering both tested and new values of $r$ are needed.

In this work, geometric parameters were correlated to reservoir water depth $(M)$ and $r$, thus generating scaling relations that allow estimations of order of magnitudes of a dam-break wave peak, for the range $0 \leq r \leq 0.4$, at initial stages of dam-break wave development. Supported by observations, we conclude that the maximum wave height and the rate of change of the maximum wave height are both directly proportional to the $r$ ratio, expressed by a non-dimensional relation - Equation 5 .

The kinematic behavior of the breaking wave appears cyclic, following flow accelerations and decelerations. The maximum velocities achieved by the waves were evaluated to allow for extrapolation (up-scaling) to real dams (prototypes). The scenarios considering downstream water level $J=0$ (dry) or $J>0$ (e.g., channel or rivers) show distinct behavior. The presence of water downstream modifies the development of the dam-break wave, particularly in terms of jet form and type of break. Also, the maximum velocity of the dam-break wave increases when combined with other physical characteristics of the dam (e.g., $M$ and $r$ ).

Despite strongly unsteady phenomena at initial stages, we suggest the use of the non-dimensional maximum height and velocity peak as qualified predictors of development of the dam-break wave. The experimental data and results from this investigation match with previous literature, thus contributing to further our understanding of the phenomenon. Practical applications of the studies for engineering design, dam operation, and risk analyses for undesirable catastrophic failure events are most significant.

\section{SUPPLEMENTAL DATA}

Some or all data, spreadsheets and footage that support the findings of this study are available from the corresponding 
author upon request. No models or codes were generated or used during the study.

\section{ACKNOWLEDGEMENTS}

The first author acknowledges Conselho Nacional do Desenvolvimento Científico e Tecnológico (CNPq) of the Brazilian Government for the support through a scholarship grant. Also, authors are thankful to the Necod team and UFRGS for allowing the use of the laboratory facilities and support throughout the undergraduate and master of science studies of the first author. Finally, the authors wish to express their gratitude to Juan J. Fedele and Léo A. Hartmann for his assistance and comments during the preparation of this manuscript.

\section{REFERENCES}

Ancey, C. (2014). Hydraulique à surface libre: crues, vagues, et ruptures de barrage. Lausanne: Laboratoire Hydraulique Environnementale, École Polytechnique Fédérale de Lausanne Écublens. Retrieved in 2020, October 16, from http://lhe.epfl.ch/cours/masterGC/ cours-hydraulique.pdf

Bukreev, V. I., \& Gusev, A. V. (2005). Initial stage of the generation of dam-break waves. Doklady Physics, 50(4), 200-203. Translated from Doklady Akademii Nauk, 401(5), 619-622.

Chanson, H. (2006). Analytical solutions of laminar and turbulent dam-break wave. In R. Ferreira, E. Alves, J. Leal \& A. Cardoso (Eds.), River flow: proceedings of the international conference on fluvial bydraulics (pp. 465-474). London: Taylor \& Francis.

Chaudhry, M. H. (2008). Open-channel flow. Boston: Springer Science+Business Media.

Duarte, R., Ribeiro, J., Boillat, J. L., \& Schleiss, A. (2011). Experimental study on dam-break waves for silted-up. reservoirs. Journal of Hydraulic Engineering, 137(11), 1385-1393.

Elkholy, M., LaRocque, L. A., Chaudhry, M. H., \& Imran, J. (2016). Experimental investigations of partial-breach dam-break flows. Journal of Hydraulic Engineering, 142(11), 04016042.

Espartel, L. (2015). Análise de fenômenos hidráulicos: emprego de câmera de alta velocidade (Final essay). Instituto de Pesquisas Hidráulicas, Universidade Federal do Rio Grande do Sul, Porto Alegre.

Espartel, L. (2019). Análise hidrodinâmica da onda gerada através da ruptura instantânea de uma barragem (Master dissertation). Instituto de Pesquisas Hidráulicas, Universidade Federal do Rio Grande do Sul, Porto Alegre.

Hsu, H.-C., Torres-Freyermuth, A., Hsu, T.-J., Hwung, H.-H., \& Kuo, P.-C. (2014). On dam-break wave propagation and its implication to sediment erosion. Journal of Hydraulic Research, 52(2), 205-218.
James, S. (2016). Learning Goal 8c: explain how wave characteristics determine the types of breaking waves. UBC ATSC 113 - Weather for Sailing, Flying and Snow Sports. Retrieved in 2020, October 16, from https://www.eoas.ubc.ca/courses/atsc113/sailing/ met_concepts/08-met-waves/8c-breaking-waves/index.html

Jánosi, I. M., Jan, D., Szabó, K. G., \& Tél, T. (2004). Turbulent drag reduction in dam-break flows. Experiments in Fluids, 37(2), 219-229.

Javadian, M., Mahmoudinasab, F., \& Kaveh, R. (2016). A study on experimental model of dam break problem and comparison experimental results with analytical solution of Saint-Venant. International Journal of Advanced Biotechnology and Research, 7(5), 1239-1245.

Khankandi, A. F., Tahershamsi, A., \& Soares-Frazão, S. (2012). Experimental investigation of reservoir geometry effect on dambreak flow. Journal of Hydraulic Research, 50(4), 376-387.

LaRocque, L. A., Imran, J., \& Chaudhry, M. H. (2013). Experimental and numerical investigations of two-dimensional dam-break flows. Journal of Hydraulic Engineering, 139(6), 569-579.

Le Méhauté, B. (1976). An introduction to bydrodynamics and water waves. Pasadena: Springer Science + Businesse Media, LLC. http:/ / dx.doi.org/10.1007/978-3-642-85567-2.

Leal, J. G. A. B., Ferreira, R. M. L., \& Cardoso, A. H. (2006). Dam-Break Wave-Front Celerity. Journal of Hydraulic Engineering, 132(1), 69-76.

Lima, D., \& Vale, J. H. (2019). Corpo é localizado no 300 dia de buscas por vítimas em Brumadinho. Estado de Minas Gerais. Retrieved in 2020, October 16, from https://www.em.com.br/app/noticia/ gerais/2019/11/20/interna_gerais,1102465/corpo-e-localizadono-300-dia-de-buscas-por-vitimas-em-brumadinho.shtml

Liu, H., \& Liu, H. (2017). Experimental study on dam-break hydrodynamic characteristics under different conditions. Journal of Disaster Research, 12(1), 198-207.

Mariño, B. M., \& Thomas, L. P. (2011). Dam-break release of a gravity current in a power-law channel section. Journal of Physics: Conference Series, 296, 012008. http://dx.doi.org/10.1088/17426596/296/1/012008.

Montz, B. E., Tobin, G. A., \& Hagelman III, R. R. (2017). Natural hazards: explanation and integration (2nd ed.). New York: The Guilford Press.

Olarn, K., Sidhu, S., \& Westcott, B. (2018, 27 July). Substandard construction' caused Laos dam collapse, minister says. CNN. Retrieved in 2020, October 16, from https:/ / edition.cnn.com/2018/07/27/ asia/laos-dam-collapse-construction-intl/index.html

Ozmen-Cagatay, H., \& Kocaman, S. (2010). Dam-break flows during initial stage using SWE and RANS approaches. Journal of Hydraulic Research, 48(5), 603-611. 
Soares-Frazão, S., \& Zech, Y. (2007). Experimental study of dambreak flow against an isolated obstacle. Journal of Hydraulic Research, 45(Suppl. 1), 27-36.

Soares-Frazão, S., \& Zech, Y. (2008). Dam-break flow through an idealised city. Journal of Hydraulic Research, 46(5), 648-658.

Stansby, P. K., Chegini, A., \& Barnes, T. C. D. (1998). The initial stages of dam-break flow. Journal of Fluid Mechanics, 374, 407-424.

Stolle, J., Ghodoosipour, B., Derschum, C., Nistor, I., Petriu, E., \& Goseberg, N. (2019). Swing gate generated dam-break waves. Journal of Hydraulic Research, 57(5), 675-687.

Vischer, D. L., \& Hager, W. H. (1998). Dam hydraulics. Chichester: Wiley.

Von Häfen, H., Goseberg, N., Stolle, J., \& Nistor, I. (2019). Gate-opening criteria for generating dam-break waves. Journal of Hydraulic Engineering, 145(3), 04019002.
Wu, J. (2014). Characterizing the dam break release (Thesis). Department of Mechanical Engineering, Massachusetts Institute of Technology, Massachussets.

\section{Authors contributions}

Lélis Espartel: Responsible for conducting the experiments, preparing the manuscript and data analyzing, discussion and writing.

Rafael Manica: Master's dissertation supervisor, guided the work, elaborated parts of the text, assisted in the data interpretation and revised the manuscript.

Editor-in-Chief: Adilson Pinheiro

Associated Editor: Iran Eduardo Lima Neto 